\title{
Continuum of Care in Speech-Language Pathology Student Placements: Identifying Key Learning Themes
}

\author{
Nicola Wardrop \\ ACT Health, Australia \\ Lindy McAllister \\ University of Sydney, Australia \\ Daniel De Stefanis \\ ACT Health, Australia \\ Felicity Martin \\ ACT Health, Australia
}

\begin{abstract}
Despite growing evidence in favour of longitudinal integrated clerkships (LICs) for medical student placements, allied health student placements continue to address single caseload types, often representing one stage of the patient journey. This study explored perceptions of speechlanguage pathology (SLP) students in a continuum of care placement in Australia, following the patient journey of stroke survivors from acute admission to rehabilitation. Four pairs of students participated in 24-day continuum of care placements. Student clinical competence was assessed in the usual way using the COMPASS® tool to ascertain if students achieved required levels of competency and were not disadvantaged by the new placement structure. Student satisfaction was assessed with a 5-point Likert scale. Learning outcomes were explored in individual semistructured interviews at conclusion of placement. Thematic analysis was undertaken on interview transcripts to identify key themes from interviews. All students achieved entry-level competency upon completion of their placement. Positive learning outcomes reported included improvement in understanding of the post-stroke journey, broadened clinical knowledge, improved adaptability to different clinical settings, and awareness of and ability to deliver patient-centred care. As a result of this placement model, students reported developing an increased sense of their professional role and responsibility in advocacy for the patient. It is recommended that continuum of care placements be considered as an alternative placement experience structure in hospital settings to enhance student learning of the patient journey.
\end{abstract}

Keywords: continuum of care experiences; placement models; placements; speechlanguage pathology students

${ }^{*}$ Corresponding Author: Nicola Wardrop, Clinical Education Unit, Level 2, Building 6, The Canberra

Hospital, Yamba Drive, Garran ACT 2605, Australia

Email: nicola.wardrop@act.gov.au

Journal URL: http://e-learning.coventry.ac.uk/ojs/index.php/pblh

Wardrop, N., McAllister, L., De Stefanis,D., and Martin, F. (2017) 'Continuum of Care in Speech-Language Pathology Student Placements: Identifying Key Learning Themes'. International Journal of Practice-based Learning in Health and Social Care, 5 (1), 24-41 


\section{(c) (i) $(9)$}

BY NC ND (C) 2017 Nicola Wardrop, Lindy McAllister, Daniel De Stefanis, and Felicity Martin. This Open Access article is distributed under the terms of the Creative Commons Attribution Attribution-NonCommercial No Derivatives 4.0 International License (https://creativecommons.org/licenses/by-nc-nd/4.0/ ), which permits unrestricted non-commercial use, distribution, and reproduction in any medium, provided the original work is properly cited and is unaltered. 


\section{Introduction}

Student placements within the allied health professions have typically taken the form of students working with specific caseloads (Sheepway, Lincoln, and Togher 2011), in a specific setting and usually representing only one stage of the patient journey (e.g., acute care phase in an acute hospital placement). Such placement models may not promote the development of knowledge and skills required for continuity of care and patient-centred care, which is becoming increasingly important in health service provision (Bennett, Fancourt, Peters, and Wu 2015). A placement model that better aligns with these concepts is emerging in some medical schools and is described as longitudinal integrated clerkships (or LICs) (Hirsh, Ogur, Thibault and Cox 2007, Hirsh, Walters, and Poncelet 2012, Sturmberg, Reid, and Khadra 2002, Walters et al. 2012).

LICs were embraced in medical education in Australia to address the dual challenges of diversifying the learning experience and professional accountability, and addressing the doctor shortage in rural and remote communities (Sturmberg, Reid, and Khadra 2002, Walters et al. 2012). LICs are clinical placements where students are involved in comprehensive clinical care of patients over time (Bates et al. 2013). LICs are usually one year in duration, and mostly in ambulatory clinics. The outcomes documented, both in Australia and the USA, demonstrated significant benefits to the development of clinical skills and professional identity for students (Walters et al. 2012), benefits in student experience (Mihalynuk, Bates, Page, and Fraser 2008), and patient experience (Poncelet et al. 2013). Expanding on the benefits to patient experience, Poncelet et al.'s (2013) study reported that patients felt their wellbeing needs were better met by students on longitudinal placements than other members of the health care team, and were able to describe how students coordinated their care, answered questions about their care, and explained medical issues and recommendations as part of their care.

Fostering the notion of continuity in student placements - including continuity of learning environment, curriculum, and supervision - is necessary in order to develop within students a greater sense of patient-centredness, awareness of professional scope of practice and better integration of theory into clinical practice (Hirsh et al. 2007, Thistlethwaite et al. 2013). The student perceptions of their learning outcomes described in recent studies suggested that students on LICs had a greater understanding of professional role, engaged in collaboration with other health care professionals more readily, had a well-developed sense of accountability for their patients, were more civic-minded, were more likely to take on an advocacy role for their patients (Teherani, Irby, and Loeser 2013; Walters et al. 2012), and performed equally well on examinations as their traditionally-placed peers (Poncelet et al. 2011).

Puvanendran et al. (2012) conducted a thematic analysis of narratives written by 44 medical students at three points during their LIC, and found that student learning focus shifted from biomedical knowledge to patient-centredness and reflecting on their understanding of long-term care. Their study demonstrated the value of learning about both clinically applicable scientific knowledge and the holistic and humanistic aspects of providing medical interventions, and suggested that LIC students' practice could change following an encounter with even a single patient's journey.

In investigating long-term effects of placement models, Gaufberg et al. (2014) compared medical students on LICs and traditional placements (i.e. multiple short rotations in different settings across the year) by repeating surveys with students 4-6 years post-placement, and found that LIC participants continued to feel better prepared for practice and were more likely to engage in health advocacy than their peers assigned traditional placements.

Students reported a high degree of satisfaction with LICs, noting that they were afforded greater responsibility, were able to actively contribute to patient care, and were treated as future colleagues or near-peers by their clinical educators (Walters et al. 2012). Continuity of supervision was another factor contributing to student satisfaction in their placements as students perceived that feedback, whether positive or negative, was authentic, just, and based 
on multiple indicators of progress when delivered by the same clinical educator throughout placement (Bates et al. 2013). Provision of feedback can be challenging for clinical educators (Kogan et al. 2012), and the notion that LICs provided a forum for honest and trusting communication between student and clinical educator was important (Bates et al. 2013). Continuity of supervision also lends itself to logical acquisition of knowledge facilitated by the clinical educator, who can incrementally build on a student's cache of clinical awareness in a manner individualised to the students' needs (Walters et al. 2012). This process of building on previous knowledge, and transitioning from peripheral to central participation with the acquisition of increased skill, is recognised in Lave and Wenger's (1991) communities of practice learning theory.

While there is a growing body of literature about longitudinal placements for medical students, limited evidence exists for such placements for allied health students. Due to the positive learning outcomes medical students have experienced with LICs, we believed this approach could be useful in speech-language pathology (SLP). Hence, our placement design aimed to provide SLP students with an experience that enabled opportunity to learn about the pathway of recovery post-stroke, along the continuum from acute through to rehabilitation. As universities prescribe the length of SLP placements, which are traditionally less than three months' duration, this study has drawn on the principles underpinning LICs and applied them to SLP student placements, rather than reproducing them. In this article, we report on the evaluation of the placement design examining SLP students' self-reported learning outcomes, satisfaction with a continuum of care placement, and their competency on a pass/fail assessment.

\section{Method}

Ethics approval for this study was granted by the area health jurisdiction's Human Research Ethics Committee, Low Risk Sub-Committee approval ETHLR.13.172.

This research took a pragmatic research approach (Feilzer 2010) using mixed methods (Creswell 2014): qualitative (semi-structured interviews - see Minichiello, Sullivan, Greenwood, and Axford, 2004) and two quantitative measures: a satisfaction survey, and a competency assessment tool (COMPASS ${ }^{\circledR}$ ) (Speech Pathology Australia, 2011). Both quantitative and qualitative approaches were needed to address the study aim and to explore students' experiences and perceptions as well as ratings.

\section{Participants}

Participants were recruited using convenience sampling (Stat Trek n.d.); that is, all eight SLP students from one university who were allocated adult placements at the tertiary hospital undertaking the study between September 2013 and December 2014, were invited by the clinical educator to participate in the study. Convenience sampling is widely used in exploratory research such as this study due to efficiency and the ability to test research questions (Aurini, Heath, and Howells 2016). Eight students consented to participate. All students were in their final year of pre-registration study undertaking their final adult placement; there were two undergraduates and six graduate entry masters of SLP student participants. Enrolment into the Masters of SLP requires completion of a relevant undergraduate degree with assumed knowledge requirements. Masters of SLP is a post-graduate entry course and on completion, students are deemed to meet entry-level requirements into the profession. Seven of the eight participants were female. Ethics approval did not give permission for further demographic details to be collected. All students completed the placements, clinical assessment requirements, satisfaction surveys, and interviews required for the study.

\section{Placement structure}

The continuum of care placement was structured to offer students the opportunity to provide comprehensive care to patients following stroke, across the care continuum. This was different 
to the previous structure of placements where students were assigned to either the acute or rehabilitation phase of care. The students attended three days per week for eight weeks (24 days) or four days per week for six weeks ( 24 days) as prescribed by their university, with half of the placement undertaken in an acute stroke unit and half of the placement undertaken in inpatient stroke rehabilitation. Students were able to follow the patient continuum from admission via the emergency department, through acute care, inpatient rehabilitation, and the off-site rehabilitation independent living unit. Each individual student was given lead responsibility for a number of patients in the acute setting. However, they were encouraged to undertake interventions as pairs and provide peer feedback. In the rehabilitation setting, students undertook more interventions autonomously. Students developed individual learning contracts with their clinical educators, defining their clinical and professional goals for the placement and considering their learning styles when defining how feedback and reflections would occur. Methods of communication between educators and students were determined at the commencement of the placement. A team teaching approach was applied where students undertook weekly tutorials on specialist clinical topics or professional skills, observation of other disciplines working with patients, and completed a quality improvement project as part of their placement.

Organisational structure of the health service dictated that, due to acute and rehabilitation services falling into different organisation divisions, different clinical educators were required for the acute and rehabilitation phases of placement. Handover between the two clinical educators occurred in the final week of the students' acute placement phase and included discussion of students' performance in relation to student performance assessment criteria, the students' progress with their personal goals recorded in their learning contracts, and individual factors influencing their placements. The students were not present for clinical educator handover as they received their feedback individually during their formal halfway assessment in the same week, which contained more detailed discussion and exemplars of their performance not always included in the handover between clinical educators.

\section{Data collection and analysis}

This research took a pragmatic research approach (Feilzer 2010) and combined qualitative methods (semi-structured interviews), and two quantitative measures: a satisfaction survey and

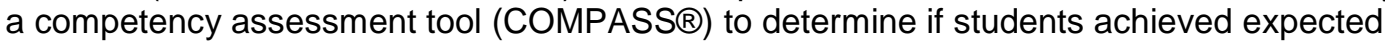
competency levels or not. Student performance against a range of clinical competencies was assessed in the usual way using the Competency Assessment in Speech Pathology (COMPASS®) tool (Speech Pathology Australia 2011). This is a validated assessment tool designed especially for SLP students. General placement satisfaction data was collected with one specific satisfaction question related to this placement structure included in the online postplacement survey and analysed as part of this study. The link to the online question was sent by email by the first author on the last day of placement. Students were asked to indicate overall satisfaction on a 5-point Likert scale ranging from 'very satisfied' to 'very dissatisfied' (refer to Figure 1 for results).

An independent interviewer, previously unknown to the students or clinical educators, conducted semi-structured interviews individually with each student on the final day of placement. Interview questions canvassed topics such as understanding of speech pathology roles, the significance of the continuum of care, and knowledge and skills developed during placement. Student names were removed from the interview transcripts and replaced with the following labelling convention: the four placements were randomly allocated a number from one to four; as students attended placement in pairs, each student was labelled as 'A' or ' $B$ '. That is, students were labelled from $1 \mathrm{~A}$ and $1 \mathrm{~B}$ through to $4 \mathrm{~A}$ and $4 \mathrm{~B}$ identifying each individual student's interview response. Student quotes labelled within this article adhere to this convention. Interviews were recorded, transcribed and subsequently analysed for themes and subthemes by two of the authors (NW and LM) using a qualitative thematic analysis approach (Braun and Clark 2006). To ensure rigor in the qualitative data analysis, these two authors read the interview transcripts and coded each one independently before meeting to compare 
identified codes and agree on a final list of codes to be used. The interviews were then recoded jointly and achieved consensus in consolidating the final number of codes. To further ensure rigor, the codes were clustered into sub-themes and the authors discussed whether coverage of all identified codes was complete, potential gaps, and appropriate labels for the sub-themes. The sub-themes were then clustered into overarching themes and labels for the themes were agreed upon.

\section{Findings}

\section{Interview analysis}

Iterative thematic analysis of the eight student interviews revealed four overarching themes: (1) the patient journey after stroke, (2) awareness of the continuum of care, (3) understanding of new knowledge and skills, and (4) the student experience of continuum of care placement. Sixteen related subthemes were identified. These themes, sub-themes, and exemplar quotes for each sub-theme are presented in the table in Appendix 1.

\section{Theme 1: The patient journey after stroke}

In discussing the patient journey after stroke during interviews, most students were able to recognise that the journey is variable; some patients take a linear path of improvement while for others, the path may be towards palliation rather than recovery. Students were also able to identify the impact of individual factors including motivation, degree of impairment, and familial supports on the patient journey and reported the need to tailor interventions to each patient and their family.

It's about putting your agenda as a professional aside and what you want to achieve aside and seeing what the person's needs are and trying to work your goals into that. (Student 1B)

The role of the patients' families was identified as a distinct sub-theme and the students were able to describe the importance of family in the journey after stroke and incorporate family goals into care plans.

Using family in this process is a really big thing. You think, "Oh, I must have all the answers", but no, they're the ones that know the client best. So that has helped me to think, I guess, more about the family's role. (Student 3B)

The transition between care settings (acute to rehabilitation) was acknowledged by the students as a previously unrecognised source of difficulty for patients. The students' description of the clinician's role in easing that transition suggested a new understanding of this aspect of patientcentred care.

\section{Theme 2: Awareness of the continuum of care}

Explicit awareness of the continuum of care was a strong theme in all the student interview responses, with all consistently identifying differences in goal setting, prioritisation, time management, clinical reasoning, and formal models of care between acute admission and rehabilitation and beyond. Some students went on to describe that this placement had foregrounded those differences for them, where previous placements in single settings had not made apparent the patient experience of a continuum of care with different clinical approaches.

To have an understanding of what it is like from start to finish is probably very important because... people might know their particular area and just sort of look at how things work within that. (Student $1 \mathrm{~A})$ 
The other sub-theme that emerged under this theme was an awareness of how acute-phase decisions influence rehabilitation-phase management. Students were able to recognise that they can influence later patient care through their involvement in collaborative decision-making and referrals and were empowered to be part of team decisions during their placement.

I guess ... the rehab doctors just using their own experience or interactions with the patients may mean they can't understand them. They will often take that to mean that the person is really confused; so it's important that the speech-language pathologists have an active role in that information. (Student $1 \mathrm{~A}$ )

\section{Theme 3: Understanding of knowledge, skills and role}

The students' understanding of knowledge, skills and role was a notable theme; however, there was some variability in the detail and emphasis individual students placed on particular skills. All students reported the importance of empathy and counselling, and all reported an improved understanding of the roles of the multidisciplinary team and their role within the team.

You need knowledge of what's going on for the patient with other professionals. It's good to have that more...involved understanding and knowledge of the client. (Student 4B)

Clinical skills gained during placement were a recurrent sub-theme. In their interviews, students referred to learning to become investigators, synthesising information from a range of sources, educating patients, and researching unfamiliar clinical presentations. They recognised the value of learning on the job and integrating theory with practice.

Three students were able to describe developing a strong sense of professional identity and, when integrated with their described understanding of evidence-based interventions, strong communication skills, and a holistic approach to patient care, these students were able to spontaneously provide some robust examples of advocating for patients along with ethical reasoning and social justice implications.

It's a busy environment, there are so many people involved. If someone doesn't step in and say, "Oh, how about we do this?" it will never happen because it's not in anyone's particular job description. (Student 1B)

\section{Theme 4: The student experience of continuum of care placement}

Under this theme, the interviews yielded sub-themes of positive experiences, challenging experiences, learning outcomes across the continuum of care, and opportunities to improve the placement. Satisfaction with continuum of care placements evoked passionate responses in all students. All students reported a relatively high degree of stress relating to the transition from acute setting to rehabilitation setting, citing a feeling of going back to novice status instead of experiencing a steady progression towards clinical competence.

I felt that after the four weeks in acute, I was starting to get there and it was great and then I was brought back down to novice and it was disempowering. (Student $3 A)$.

In a traditional placement (less than three months), students are usually placed in one setting with one specific caseload where a transition between clinical settings is not required and therefore progressive clinical competency is usually experienced.

However, all but one student reflected that, in the end, the effect of the placement structure on their overall skills and their understanding of patient journey and continuity of care was a positive one. The same students stated that the continuum of care experience was preferable to a placement in a single clinical area and that they would elect to undertake such a placement again. 
I think it has been really good to see the differences between the settings acute and rehab because ... if you only had one or the other, there'd be quite a lot that you were missing out on. (Student $1 \mathrm{~A}$ )

The feeling of returning to a novice level of practice was notable in that it made explicit to the students their own limitations that may not have been apparent to them if they had only been placed in one clinical setting. One student felt that the placement was inappropriate due to the amount of stress it caused and was unable to identify positive learning outcomes unique to this placement structure.

From a learning perspective, my overall opinion is that this is not a good idea. It's just not an opportunity for us to really feel that we've got our feet in an area.

(Student 3A)

Most students were keen to suggest opportunities for improving the placement, including increased exposure to the rehabilitation setting prior to transition, increasing the number of contact days per week from three to four, or reversing the order of placement from rehabilitation to acute care.

\section{Clinical competence}

All students' achieved entry-level competence on COMPASS $\AA$ on completion of the placement, consistent with student performance on traditional placements.

\section{Student satisfaction}

Seven out of the eight students involved in this study reported that they were 'satisfied' or 'very satisfied' with their placement on a 5-point Likert scale (see Figure 1). The student who reported dissatisfaction with the placement was the same student who reported a high degree of stress.

Figure1: Overall student satisfaction with placement

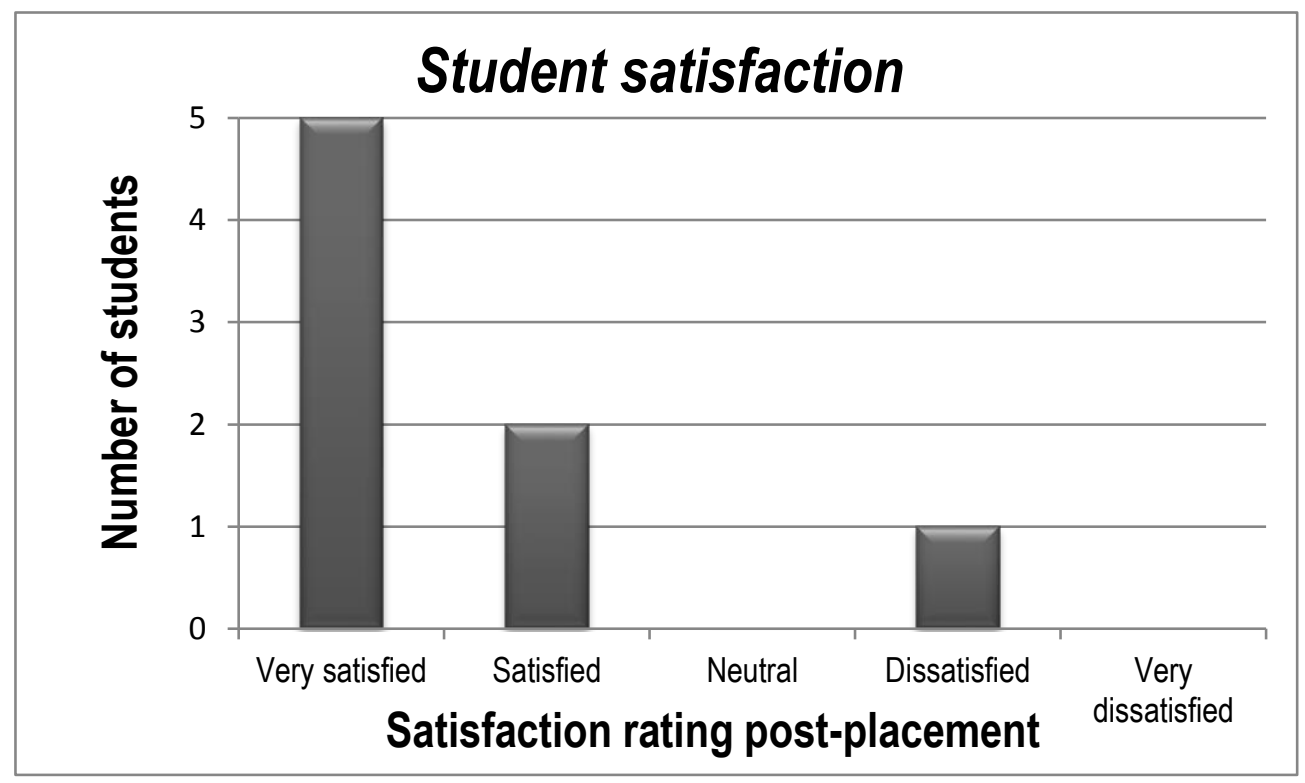




\section{Discussion}

The available evidence for LICs had a distinct medical focus, however, the underpinning principles of continuity of learning environments, curriculum and supervision described by Hirsh et al. (2007) have applicability to the allied health professions. The outcomes described in the literature for students' learning and professional orientation, as well as patient-centred care, were also applicable to allied health student education. This study aimed to provide SLP students with a placement design incorporating the principles of continuity of care detailed in LIC literature. Pure replication of LIC was not possible due to a number of restrictions, including placement durations set by universities for SLP students and the organisational structure where the continuum of care placement was trialled. As a result, the placement was structured with a number of deviations from the medical LIC model. Deviations included shorter placements of up to 24 days over a six-week period, sequential clinical supervisors with handover of supervision mid-placement required, and immersion in one aspect of the continuum of care at a time with students placed in the acute phase for the first half of the placement and rehabilitation for the second half. As such, true immersion in the progressive continuum of the patient journey following was stroke was not possible.

The themes and sub-themes that were identified through student interviews reveal that SLP students on continuum of care placements learned to recognise and understand the post-stroke patient journey and differences in clinical approach and priorities at various stages of the continuum. The opportunity afforded by continuum of care placements to observe several stages of the patient journey has provided the students with the opportunity to broaden clinical knowledge, adapt to different settings, deliver patient-centred care, and take greater responsibility for patient outcomes. While it was not a focus of this placement model, knowledge of multidisciplinary roles was an area of increased awareness and contemplation for the students. There was evidence of students engaging in role clarification of their own role and that of other professionals, which supported their progression towards interprofessional collaborative practice (Canadian Interprofessional Health Collaborative (CIHC) 2010). This could be extended in future placements to encompass true interprofessional learning, where students learn with, from and about each other's professions, and are thereby better prepared for collaborative practice to contribute to better health outcomes for their patients in their careers (World Health Organization 2010). Some of the students became aware of social justice issues and ethical accountability for their patients in order to act as advocates. This was a highly desirable result in line with the improved sense of idealism described in the LIC literature (Gaufberg et al. 2014) and also demonstrated the well-rounded clinical skills and confidence in their role that is required to build and describe the clinical and psychosocial aspects of a case to the wider team or stakeholders in order to facilitate care. Dall'Alba (2009) describes the importance of education programs that include awareness of professional ways of being, not just theoretical knowledge and skill acquisition, as key to developing professional identity and integrating all that students have learned into being a health professional. This model of placement strives to promote this concept and, we believe, goes some way towards achieving it.

All students' achieved entry level competence on COMPASS $\AA$ on completion of the placements. Although our study did not compare competence with students on continuum of care placement versus other placement structures, this finding is consistent with findings in the medical student literature that students on LICs perform as well as their peers on academic performance (Poncelet et al. 2011, Walters et al. 2012). The majority of students were 'satisfied' to 'very satisfied' with their placement overall; this suggests that this model of placement was a positive learning experience. One student in the study expressed dissatisfaction with the placement as not being conducive to acquiring or consolidating clinical or professional skills. This student reported a preference for traditional placement structures in one phase of the care continuum (i.e. either rehabilitation or acute). The continuum of care model may not suit all students' learning styles and temperaments and may challenge students with expectations of a traditional clinical placement. 
The ability to recognise transferable knowledge and skills across the continuum was somewhat variable among students' interview responses, with transition stress high as students transitioned between clinical settings. Possible causal factors may include different prior experiences the students had with adult patients in hospital or rehabilitation settings. Students were drawn from the undergraduate program and some from the Masters of SLP program, representing differences in maturity, background knowledge, and experience. Although the students' prior knowledge and experiences were not explored in this study, it is plausible that their ability to generalise prior learning across clinical settings and placements presented a challenge for them (Sheepway, Lincoln, and McAllister 2014). This aspect of competence is particularly important in the context of increased demand for placements, where it may not be possible for education providers to expose students to all clinical populations and recognition of transferrable knowledge and skills is essential.

One of the limitations of this study was in the structure and supervision of the placement, which necessarily deviated from the typical LIC structure described in the literature. Firstly, SLP students are never placed on year-long clerkships (Sheepway, Lincoln, and McAllister 2014); the SLP placements provided were 24 days long, over 6 or 8 weeks depending on the university placing the students. This study did not examine the potential effects of the different duration of the placement on the outcomes. Secondly, the current structure is such that the students complete each stream in turn, rather than concurrently. A review of the structure following this study has established a placement model more in line with the literature, with students undertaking acute and rehabilitation duties concurrently under their respective clinical educators (see Figure 2), further enhancing the opportunity for students to learn the stroke continuum and provide continuity of care. This revised model is already being put into practice and forms phase two of the study. The students continue to undertake the placements in pairs and continue to receive supervision from separate acute and rehabilitation specialist SLP clinical educators. The small sample size was a limitation of this study, data collection is ongoing and future analyses will provide larger sample sizes.

Figure 2: Placement structure

\begin{tabular}{|c|c|c|}
\hline & First Half & Second Half \\
\hline \multirow[t]{2}{*}{ Current structure } & Acute 3 days/week & $\begin{array}{c}\text { Rehabilitation } 3 \\
\text { days/week }\end{array}$ \\
\hline & \multicolumn{2}{|c|}{ University coursework 2 days/week } \\
\hline \multirow[t]{3}{*}{ Proposed structure } & $\begin{array}{c}\text { Rehabilitation } 3 \\
\text { days/week }\end{array}$ & Acute 3 days/week \\
\hline & Acute 1 day/week & Rehabilitation 1 day/week \\
\hline & \multicolumn{2}{|c|}{ University coursework 1 day/week } \\
\hline
\end{tabular}

While this study did not explicitly investigate the causes of the transition stress reported by all students, high stress levels were reported by the students. Students described the feeling of returning to novice level upon rotation into the second (rehabilitation) clinical setting and, although not explicitly stated, the transition to a different clinical educator may have contributed to transition stress. Lekkas et al. (2007) identified that multiple supervisors create a sense of discontinuity for students. To reduce this sense of discontinuity, where a multiple supervisor model of clinical education is necessary, it is recommended that it be collaborative and that the student is well prepared, including agreement on formal and informal methods of communication between all educators and students at commencement of the placement. Attempts were made to reduce transition stress with the students meeting with both clinical educators mid-placement to identify the particular knowledge and professional skills 
transferrable between clinical settings. This included reflection on communication, negotiation, critical thinking, problem solving, advocacy, multidisciplinary teams, and the students' professional identity and role. As student interviews did not reflect awareness of their transferrable knowledge and skills between clinical settings, the discussion held by clinical educators may not have been explicit or understood by the students. Future opportunities to reduce student stress with this placement structure include improved clinical educator and student reflection acknowledging transferrable competencies, development of a collaborative communication plan at the commencement of the placements, inclusion of educators and students at mid placement handover and student performance evaluations, and adjusting the placement structure by undertaking both settings concurrently. Due to departmental structure, two different clinical educators will continue to be required; however, both will be concurrently involved in supporting the student through the duration of the placement. One of the aspects of a paired placement not investigated in this study was that of peer support. While we acknowledge the benefits of peer learning (Baldry Currens 2003), peer support and feedback to each other was not emphasised to students in this placement and was not specifically evaluated.

Peer support did not emerge as a theme in the interviews, and therefore the benefits or otherwise were not discussed in this article.

In summary, we found four major themes that demonstrate that, for our cohort of students, the continuum of care placement model appears to offer some significant benefits. Similar to conclusions discussed in the literature regarding LICs, this continuum of care, allied health student placement resulted in increased awareness of the patient journey and the flexibility of clinical skills that go with this awareness. Important positive outcomes discussed in the LIC literature, namely, an increased sense of professional role and advocacy for patients, were also reflected in the SLP student interviews when commenting on our continuum of care placement.

Continuum of care placement models are a developing area in allied health clinical education and the authors of this study are committed to further refinement and evaluation of the model. We plan to review the outcomes of our new placement structure and include formal evaluation of clinical educator perspectives. Another future direction may be a comparative study between allied health students undertaking continuum of care placements, and those on traditional, single-setting placements. It might also be possible, in the future, to examine the effect of longer placements, or more placement days, on student perceptions of continuum of care placements.

\section{Acknowledgements}

We wish to thank the Chief Allied Health Officer, Karen Murphy, who supported this study, and the students and student clinical educators who participated in the study. We also extend our thanks to Ms Lauren Brooks, Ms Annette Carroll, and Ms Rosy Winter for conducting the student interviews, and to Ms Annette Carroll for also transcribing the student interviews. 


\section{References}

Aurini, J., Heath, M., and Howells, S. (2016) The How To of Qualitative Research: Strategies for Executing High Quality Projects. Thousand Oaks, CA: Sage.

Baldry Currens, J. (2003) 'The 2:1 clinical placement model: Review'. Physiotherapy, 89 (9), 540-554 https://doi.org/10.1016/S0031-9406(05)60180-0

Bates, J., Konkin, J., Suddards, C., Dobson, S., and Pratt, D. (2013) 'Student Perceptions of Assessment and Feedback in Longitudinal Integrated Clerkships'. Medical Education, 47 (4), 362-374 http://onlinelibrary.wiley.com/doi/10.1111/medu.12087/full

Bennett, S., Fancourt, N., Peters, D., and Wu, A. (2015) 'Global Strategy on People-Centred and Integrated Health Services, Interim Report for the World Health Organization'. [online] available from http://apps.who.int/iris/bitstream/10665/155002/1/WHO HIS SDS 2015.6 eng.pdf?ua= $\underline{1 \& u a=1}$ [4 July 2015]

Braun, V. and Clarke, V. (2006) 'Using thematic analysis in psychology'. Qualitative Research in Psychology, 3 (2), 77-101 https://doi.org/10.1191/1478088706qp063oa

Canadian Interprofessional Health Collaborative (2010) A National Interprofessional Competency Framework. [online] available from http://www.cihc.ca/files/CIHC IPCompetencies Feb1210.pdf [20 December 2016]

Creswell, J. W. (2014) Research Design: Qualitative, Quantitative, and Mixed Methods Approaches. 4th edn. Thousand Oaks, CA: Sage.

Dall'Alba, G. (2009) 'Learning professional ways of being: Ambiguities of becoming'. Educational Philosophy and Theory, 41 (1), 34-45 http://dx.doi.org/10.1111/i.1469$\underline{5812.2008 .00475 . x}$

Feilzer, M.Y. (2010) 'Doing mixed methods research pragmatically: Implications for the rediscovery of pragmatism as a research paradigm'. Journal of Mixed Methods Research, 4 (1), 6-16. https://doi.org/10.1177/1558689809349691

Gaufberg, E., Hirsh, D.A., Krupat, E., Ogur, B., Pelletier, S., Reiff, D., and Bor, D. (2014) 'Into the future: Patient-centredness endures in longitudinal integrated clerkship graduates'. Medical Education, 48 (6), 572-582 https://doi.org/10.1111/medu.12413

Hirsh, D.A., Ogur, B., Thibault, G.E., and Cox, M. (2007) "Continuity" as an organizing principle for clinical education reform'. The New England Journal of Medicine, 356 (8), 858-866 https://doi.org/10.1056/NEJMsb061660

Hirsh, D.A., Walters, L., and Poncelet, A.N. (2012) 'Better learning, better doctors, better delivery system: Possibilities from a case study of longitudinal integrated clerkships'. Medical Teacher, 34 (7), 548-554 http://dx.doi.org/10.3109/0142159X.2012.696745

Kogan, J.R., Conforti, L.N., Bernabeo, E.C., Durning, S.J., Hauer, K.E., and Holmboe, E.S. (2012) 'Faculty staff perceptions of feedback to residents after direct observation of clinical skills'. Medical Education, 46 (2), 201-215 https://doi.org/10.1111/j.13652923.2011.04137.x

Lave, J. and Wenger, E. (1991) Situated Learning: Legitimate Peripheral Participation. Cambridge, UK: Cambridge University Press https://doi.org/10.1017/CBO9780511815355 
Lekkas, P., Larsen, T., Kumar, S., Grimmer, K., Nyland, L., Chipchase, L., Jull, G., Buttrum, P., Carr, L., and Finch, J. (2007) 'No model of clinical education for physiotherapy students is superior to another: A systematic review'. Australian Journal of Physiotherapy, 53, 19-28 https://doi.org/10.1016/S0004-9514(07)70058-2

Mihalynuk, T., Bates, J., Page, G., and Fraser, J. (2008) 'Student learning experiences in a longitudinal clerkship programme'. Medical Education, 42 (7), 729-732 https://doi.org/10.1111/j.1365-2923.2008.03040.x

Minichiello, V., Sullivan, G., Greenwood, K., and Axford, R. (eds.) (2004) Handbook of Research Methods in Nursing and Health Science. Sydney: Pearson Education.

Poncelet, A., Bokser, S., Calton, B., Hauer, K.E., Kirsch, H., Jones, T., ... and Robertson, P. (2011) 'Development of a longitudinal integrated clerkship at an academic medical centre'. Medical Education Online, 16, 5939. available from https://doi.org/10.3402/meo.v16i0.5939

Poncelet, A.N., Wamsley, M., Hauer, K.E., Lai, C., Becker, T., and O'Brien, B. (2013) 'Patient views of continuity relationships with medical students'. Medical Teacher, 35 (6), 465471 https://doi.org/10.3109/0142159X.2013.774335

Puvanendran, R., Vasanwala, F.F., Kamei, R.K., Hock, L.K., and Lie, D.A. (2012) 'What do medical students learn when they follow patients from hospital to community? A longitudinal qualitative study'. Medical Education Online, 17, 18899. available from https://doi.org/10.3402/meo.v17i0.18899

Sheepway, L., Lincoln, M., and McAllister, S. (2014) 'Impact of placement type on the development of clinical competency in speech-language pathology students'. International Journal of Language and Communication Disorders, 49 (2), 189-203 https://doi.org/10.1111/1460-6984.12059

Sheepway, L., Lincoln, M., and Togher, L. (2011) 'An international study of clinical education practices in speech-language pathology'. International Journal of Speech-Language Pathology, 13 (2) 174-185 https://doi.org/10.3109/17549507.2011.491129

Speech Pathology Australia (2011) COMPASSA: Competency Assessment in Speech Pathology. Melbourne, Australia: The Speech Pathology Association of Australia Ltd.

Stat Trek (n.d.) Convenience Sampling. [online] available from http://stattrek.com/statistics/dictionary.aspx?definition=convenience sample [1 July 2015]

Sturmberg, J.P., Reid, S., and Khadra, M.H. (2002) 'A longitudinal, patient-centred, integrated curriculum: Facilitating community-based education in a rural clinical school'. Education for Health, 15 (3), 294-304 doi: 10.1080/1357628021000012787

Teherani, A., Irby, D.M., Loeser, H. (2013) 'Outcomes of different clerkship models: longitudinal integrated, hybrid, and block'. Academic Medicine, 88 (1), 35-43 https://doi.org/10.1097/ACM.0b013e318276ca9b

Thistlethwaite, J.E., Bartle, E., Chong, A.A.L, Dick, M., King, D., Mahoney, S., ... and Tucker, G. (2013) 'A review of longitudinal community and hospital placements in medical education: BEME Guide No. 26'. Medical Teacher, 35 (8), e1340-e1364 https://doi.org/10.3109/0142159X.2013.806981 
Walters, L., Greenhill, J., Richards, J., Ward, H., Campbell, N., Ash, J., and Schuwirth, L.W.T. (2012) 'Outcomes of longitudinal integrated clinical placements for students, clinicians, and society'. Medical Education, 46 (11), https://doi.org/10.1111//.13652923.2012.04331.x

World Health Organization (2010) Framework for Action on Interprofessional Education \& Collaborative Practice. [online] available from http://www.who.int/hrh/resources/framework action/en/ [20 December 2016] 


\section{Appendix 1}

Student quotes were labelled using the following convention: the four placements studied were randomly allocated a number $1-4$; the two students on each placement were then labelled as ' $A$ ' or 'B' (e.g. student 1B or student $3 A$ ).

Table 1: Thematic analysis of student interviews with illustrative quotes

\begin{tabular}{|c|c|c|}
\hline Themes & Sub-themes & Quotes \\
\hline \multirow[t]{4}{*}{$\begin{array}{l}\text { Patient journey } \\
\text { after stroke }\end{array}$} & $\begin{array}{l}\text { Variability of journey } \\
\text { across/between patients }\end{array}$ & $\begin{array}{l}\text { 'I guess that showed me that the patient } \\
\text { journey isn't always to recovery and the } \\
\text { families still need support in that case.' } \\
\text { Student } 2 B \\
\text { 'Everyone reaches it at different speeds and } \\
\text { not everyone gets there in the end so I don't } \\
\text { make assumptions any more...because I can } \\
\text { see all the factors that impact on recovery.' } \\
\text { 2B } \\
\text { 'There was one patient that came in....and he } \\
\text { almost totally resolved but there was } \\
\text { someone else who had it (CVA) in a really } \\
\text { similar area that had a really poor prognosis.' } \\
4 B\end{array}$ \\
\hline & $\begin{array}{l}\text { The need for patient- } \\
\text { centred care }\end{array}$ & $\begin{array}{l}\text { '.... seeing the person as a whole person not } \\
\text { just a speech pathology patient but as } \\
\text { someone who needs all kinds of different } \\
\text { interventions to help with their recovery.' 2B } \\
\text { 'Having a holistic attitude.... in how to provide } \\
\text { support.' 3B } \\
\text { 'Keeping in routines because getting them } \\
\text { out of routines and going whenever you want } \\
\text { can be really unsettling for them (patients), } \\
\text { especially in rehab.' 4B }\end{array}$ \\
\hline & $\begin{array}{l}\text { The role of the patient's } \\
\text { family }\end{array}$ & $\begin{array}{l}\text { 'Every person in the family is actually also an } \\
\text { individual. The patient and the family view } \\
\text { might not be the same.' } 2 \mathrm{~B} \\
\text { 'I have seen how important family support } \\
\text { can be. You think "I must have all the } \\
\text { answers", but no, they are the ones that } \\
\text { know the client best. That's helped me think } \\
\text { more about the family's role.' } 3 \mathrm{~B}\end{array}$ \\
\hline & $\begin{array}{l}\text { Difficult transition for the } \\
\text { patient to different stages } \\
\text { in care }\end{array}$ & $\begin{array}{l}\text { 'I think it's probably quite a hard transition for } \\
\text { some of them to make.' } 1 \mathrm{~A} \\
\text { 'I've seen (the patient) transit from acute all } \\
\text { the way to rehab and l've seen the transition } \\
\text { of the mother. The mum was really } \\
\text { frustrated.' } 2 A \\
\text { 'I learned more about... acknowledging when } \\
\text { the journey is going to be tougher for certain } \\
\text { patients.' 4B }\end{array}$ \\
\hline
\end{tabular}




\begin{tabular}{|c|c|c|}
\hline \multirow[t]{3}{*}{$\begin{array}{l}\text { Awareness of the } \\
\text { continuum of care }\end{array}$} & $\begin{array}{l}\text { Differences in clinical } \\
\text { reasoning along the } \\
\text { continuum }\end{array}$ & $\begin{array}{l}\text { 'It was amazing to see the same hospital, the } \\
\text { same team, but completely different sort of } \\
\text { approaches.' } 2 B \\
\text { 'You're seeing the different needs of a patient } \\
\text { in both settings.' } 2 B \\
\text { 'Everything is fast-paced and the priority is } \\
\text { just the safety of the patient whereas } \\
\text { downstairs in rehab it's more focused on } \\
\text { actual therapy.' } 1 A \\
\text { 'In an acute setting, we focus a lot on } \\
\text { impairment-based therapy but as we went on } \\
\text { to rehab I think we were thinking outside the } \\
\text { box.' } 2 A \\
\text { 'It seems really separate.' 4B }\end{array}$ \\
\hline & $\begin{array}{l}\text { Differences in goal setting } \\
\text { and time management }\end{array}$ & $\begin{array}{l}\text { 'I know that acute is much more medical, } \\
\text { much more urgent, and rehabilitation has } \\
\text { more time and space to make those } \\
\text { decisions.' } 3 \mathrm{~A} \\
\text { 'The focus is on ensuring patients are safe } \\
\text { and once they move to rehab there is a lot } \\
\text { more....in depth assessment and therapy.' } 4 \mathrm{~A}\end{array}$ \\
\hline & $\begin{array}{l}\text { Awareness of how acute } \\
\text { phase decisions influence } \\
\text { rehabilitation phase } \\
\text { management }\end{array}$ & $\begin{array}{l}\text { 'Your decisions that you make about } \\
\text { prognosis, about what is going to happen to } \\
\text { the patient, definitely affects the acute to the } \\
\text { rehab stage.' } 2 \text { A } \\
\text { 'Getting them started on something they can } \\
\text { use so the rehab (team) can pick it up and } \\
\text { run with it.' 4B } \\
\text { '(It's) helpful in informing your impression of } \\
\text { where the client's coming from and } \\
\text { what...you might expect in the future.' 4A }\end{array}$ \\
\hline $\begin{array}{l}\text { Understanding of } \\
\text { knowledge, skills } \\
\text { and role }\end{array}$ & $\begin{array}{l}\text { Communication and } \\
\text { empathy }\end{array}$ & $\begin{array}{l}\text { 'It's about being very up-front about what is } \\
\text { happening now and what is going to happen. } \\
\text { Breaking things down. I think that's much } \\
\text { better for the patient to understand.' } 2 \mathrm{~A} \\
\text { 'I've learned a lot on this placement about } \\
\text { how to provide information for patients.' } 4 \mathrm{~A} \\
\text { 'What is really important to me is empathy. } \\
\text { Understanding what the patient or their family } \\
\text { is going through.' } 3 \mathrm{~A}\end{array}$ \\
\hline & $\begin{array}{l}\text { Knowledge of } \\
\text { multidisciplinary roles }\end{array}$ & $\begin{array}{l}\text { 'It's so much better when you can bounce } \\
\text { ideas off your colleagues, like the physios } \\
\text { and the OTs.' } 2 \mathrm{~A} \\
\text { 'I definitely have a better understanding of } \\
\text { how the team works as a whole. I know who I } \\
\text { can ask when I need information.' 1A } \\
\text { 'I am just coming to a point where I know } \\
\text { when to refer and when to support my } \\
\text { patient.' 2A } \\
\text { 'You need to know what's going on in the } \\
\text { patient with other professionals...and be able } \\
\text { to pass them on to the right people.' 4B }\end{array}$ \\
\hline
\end{tabular}




\begin{tabular}{|c|c|c|}
\hline & $\begin{array}{l}\text { Sense of role and } \\
\text { professional identity }\end{array}$ & $\begin{array}{l}\text { 'It located me in relation to that person. I felt } \\
\text { like...that person has got that huge } \\
\text { progression in their life from stroke to } \\
\text { recovery and I fit in here.' Student 2B } \\
\text { 'Before, I thought therapy is the therapy } \\
\text { session and I hadn't really thought every } \\
\text { interaction with a family member, a phone } \\
\text { call or whatever, that's as important.' } 2 \mathrm{~B} \\
\text { 'You are the clinician. They have come to you } \\
\text { for this therapy and you have to take charge } \\
\text { and give it to them.' } 4 \mathrm{~B}\end{array}$ \\
\hline & $\begin{array}{l}\text { Advocacy for patients and } \\
\text { idealism }\end{array}$ & $\begin{array}{l}\text { 'It was an achievement to break through that } \\
\text { (communication) barrier but also, why wasn't } \\
\text { it (the referral) done earlier?' 2A } \\
\text { 'There are so many people involved. If } \\
\text { someone doesn't step in and say, "How } \\
\text { about we do this?" it will never happen } \\
\text { because it's not in anyone's particular job } \\
\text { description. I think it's really important for } \\
\text { health professionals.' 1B }\end{array}$ \\
\hline & $\begin{array}{l}\text { Clinical skills: evidence- } \\
\text { based care, synthesising } \\
\text { information, educating and } \\
\text { modelling }\end{array}$ & $\begin{array}{l}\text { 'You get a lot of conflicting information....and } \\
\text { you're trying to manage, "what kind of } \\
\text { baseline are we dealing with?"' } 3 \text { A } \\
\text { 'I've been trying to synthesise information } \\
\text { about a patient from a range of sources...to } \\
\text { build an idea.' 4A } \\
\text { 'I had a respiratory patient which was great } \\
\text { and...I had to go away and read how it } \\
\text { impacts on swallow.' 1A } \\
\text { 'As a health professional, lots of teaching of } \\
\text { what it is that you're doing...lots of modelling } \\
\text { and demonstrating.' 1A } \\
\text { 'In terms of clinical skills, (you need) } \\
\text { evidenced practice and teamwork.' } 2 \mathrm{~A}\end{array}$ \\
\hline $\begin{array}{l}\text { The student } \\
\text { experience of } \\
\text { continuum of care } \\
\text { placements }\end{array}$ & Positive experiences & $\begin{array}{l}\text { 'It's been a fantastic placement. I'm just going } \\
\text { to say it outright.' } 2 A \\
\text { 'I think the way the placement has been } \\
\text { organised, so } 3 \text { weeks in acute and } 3 \text { weeks } \\
\text { in rehab, has been really helpful.' } 4 \text { A } \\
\text { 'I think it has been really good to see the } \\
\text { differences between the settings acute and } \\
\text { rehab because...if you only had one or the } \\
\text { other, there'd be quite a lot that you were } \\
\text { missing out on.' } 1 \text { A } \\
\text { 'Nobody ever second guessed me or wanted } \\
\text { to check with my supervisor. Everybody was } \\
\text { happy to treat me professionally, which was } \\
\text { really nice.' } 1 \mathrm{~A}\end{array}$ \\
\hline
\end{tabular}




\begin{tabular}{|l|l|l|}
\hline Challenging experiences & $\begin{array}{l}\text { 'I found it a little bit difficult. We...sort of went } \\
\text { back to being in the first week almost.' 1A } \\
\text { 'I felt that after the four weeks in acute, I was } \\
\text { starting to get there and it was great and then } \\
\text { I was brought back down to novice and it was } \\
\text { disempowering.' 3A } \\
\text { 'I felt like at the end of the acute I was } \\
\text { starting to get quite confident and then just } \\
\text { whisked away...I was starting from scratch.' } \\
\text { 3B }\end{array}$ \\
\hline \multirow{1}{*}{$\begin{array}{l}\text { Learning outcomes gained } \\
\text { across the continum of } \\
\text { patient settings }\end{array}$} & $\begin{array}{l}\text { 'Improving my reasoning...has been } \\
\text { something l've developed a lot in this } \\
\text { placement.' 2A }\end{array}$ \\
& $\begin{array}{l}\text { 'Mainly, we've learned the holistic } \\
\text { management of the patient.' 2A } \\
\text { 'Being an investigator, that's a big skill.' 3B } \\
\text { 'I think l'm getting better at adapting to } \\
\text { situations.' 3B }\end{array}$ \\
& $\begin{array}{l}\text { 'Management of time and prioritising.' 4B } \\
\text { Opportunities for } \\
\text { improving the placement } \\
\text { experience }\end{array}$ & $\begin{array}{l}\text { 'It should be at least a four day a week } \\
\text { placement because I think...you don't get a } \\
\text { lot of continuity with patients.' 2A }\end{array}$ \\
\hline
\end{tabular}

